\title{
Counselling in primary care? Expectations, values and effectiveness*
}

\author{
MARgReet Puetz, Senior Registrar in Psychiatry, Queen Elizabeth Hospital, \\ King's Lynn, Norfolk PE30 4ET
}

On 6 November 1992 about 320 counsellors, GPs, psychiatrists and other mental health professionals participated in a one-day conference on counselling in primary care organised at St George's Hospital, London. To my surprise only about $3 \%$ of the delegates were psychiatrists. Since counselling in primary care is an important psychiatric service, one would expect that psychiatrists, in view of their role in service planning, would like to be informed about developments in this field.

After a welcome from Professor Arthur Crisp, Chairman of the British Association for Social Psychiatry, Dr Graham Curtis Jenkins, Director of The Counselling In Primary Care Trust, started by giving his view on the nature of counselling in primary care. He emphasised brief intervention therapy, stating that $85 \%$ of patients, if given the choice, would come for an average of five to six sessions. This predilection for short-term therapy was confirmed by other speakers later on. Dr Jenkins called for specific training programmes and for more attention to audit. The latter subject was elaborated on by $\mathrm{Dr}$ Roslyn Corney, Senior Lecturer at the Institute of Psychiatry. She discussed the problems of evaluation of the counsellor's work, emphasising the importance of qualitative studies despite methodological difficulties (such as lack of standardisation of measures of outcome).

Ms Helen Baws, Counsellor, opened up the discussion on issues of confidentiality and teamwork. Dr Richard Botelho, Associate Professor of Family

* A multidisciplinary conference organised by The British Association for Social Psychiatry, 6 November 1992.
Medicine and Psychiatry in New York, explored the issue of teamwork further. He elaborated on the value of negotiation both among professionals and with the patient. Mannie Sher brought his psychoanalytical background to bear by reminding us of the unconscious group processes at work in any team and Dr Paul Freeling extended this by referring to the phenomenon described by Michael Balint of "collusion of anonymity" leading to "dilution of responsibility" when a difficult patient is referred on and on. He warned GPs not to give up the "essential tasks of personal continuing whole problem care". A counsellor's input into the primary health care team as facilitator and supervisor might promote the latter. This role of facilitator is shared by psychiatrists who undertake liaison work with GPs (following Balint). Interestingly, the striking role overlap between counsellers and different mental health disciplines remained an ungrasped nettle.

Ms Viv Ball, Counsellor, dealt with the issues of training and accreditation. At present there are no consistent national standards for counsellors, but the British Association of Counsellors is working towards a national system of accreditation and registration.

The increasingly higher profile and professionalisation of counsellors is of importance to psychiatrists in the UK today. More and more general practices will become fundholding and will be recruiting their own counsellors. These changes at the level of primary care will greatly affect specialist care. Psychiatrists concerned with service planning cannot afford not to be informed about developments in primary health care, or they may find themselves overtaken by events. 